\title{
La potestad reglamentaria del Municipio en materia de funcionarios. Su órbita y tramitación.
}

Toca hoy la tarea a tema tan sencillo que quizá no la merezca con el afán que la emprendemos; pero seguimos en la confianza de que en algún sitio hará provecho, ya que siendo difícil a mucha gente ponerse de acuerdo para la apreciación de las cosas, es en lo fácil donde, con más frecuencia, se suele discrepar; y en la materia, ya hemos visto alguna que otra discrepancia, en que la razón, con todo respeto sea dicho, salió bastante mal parada, con perjuicio, naturalmente, de los funcionarios. Motivo que, por sí solo, puede que justifique nuestro propósito de contribuir al esclarecimiento de dudas y confusiones, surgidas, como siempre, en la ligera interpretación de nuestro Derecho.

¿Pretexto? La tramitación de los expedientes de Reglamentos internos de funcionarios, y los de jubilación y pensión de los mismos.

Las opiniones y criterios, sin concierto también en este particular, nos traen a un minucioso estudio que ofrecemos en pro de la inte. ligencia y conciliación de pareceres. Cumple, en primer lugar, sentar el principio de la potestad reglamentaria del Municipio en la materia.

Ya el Estatuto, en su artículo 150, la establecía y copiamos: “Es de la exclusiva competencia de los Ayuntamientos, subordinada tan sólo a las leyes generales del reino y a lo que la Ley dispone: ...30.-Reglamentación de servicios, dependencias y funcionarios del Municipio.»)

En la Ley de 31 de octubre de 1935 continúa esta potestad: "Artículo 102.-B. Potestad de ordenanzas. Aprobación de Reglamentosm. Y la Base 20 de la nueva Ley de 1945 mantiene igual potestad y principio de competencia : “En la esfera de su competencia podrán los 
"Ayuntamientos aprobar Ordenanzas y Reglamentos... Ni unos ni »otros podrán contener preceptos opuestos a las leyes.»

¿En qué medida se regula el ejercicio de esta potestad? Decía el artículo 248 del Estatuto: "Los Ayuntamientos estarán obligados a formar Reglamentos que determinen las condiciones de ingreso, ascensos, sueldos, sanciones, separaciones, derechos pasivos, funciones y deberes de los empleados municipales.) "Dichos Reglamentos deberán ser distintos para el personal técnico, administrativo y subalterno $\mathrm{y}$ han de ajustarse a los siguientes principios fundamentales:

»a), La destitución del funcionario sólo podrá hacerse por causa "grave, taxativamente prevista en el Reglamento y previo expedien"te en que sea oído el interesado.

„b) Las suspensiones gubernativas de empleo y sueldo con ca»rácter disciplinario o preventivo, no podrán exceder de dos meses.

wc) La mitad, cuando menos, de las vacantes han de concederse a la mayor antigüedad dentro del escalafón.

»d) Todos los años publicarán los Ayuntamientos el escalafón »de sus funcionarios.

»e) Deberán establecerse categorías asimiladas, en lo posible, "a los funcionarios del Estado.

"v) Los acuerdos de destitución exigirán siempre el voto favora"ble de dos terceras partes de la Corporación.

"Los obreros municipales quedarán sujetos a las leyes reguladowras del trabajo, y los Ayuntamientos tendrán respecto de ellos las nobligaciones que incumben a todo patrono.»

El artículo 93 bis del Reglamento dispone: "Los Reglamentos que, en virtud de lo dispuesto en el artículo 248 del Estatuto municipal, están obligados a redactar los Ayuntamientos para el régimen de sus funcionarios, técnicos, administrativos y subalternos, contendrán los principios fundamentales que el citado artículo y este Reglamento establecen, y serán aprobados por el Ayuntamiento y mayoría absoluta de sus concejales, teniendo el carácter de Estatuto Jegal de los Cuerpos de funcionarios municipales.)

Tales principios, con los demás preceptos del Reglamento de 1924, especialmente referidos a secretarios e interventores, constituyen lo que justamente se ha de llamar normas legislativas, en cuya órbita ha de desarrollarse dicha potestad en su acción determinante de los «deberes, derechos, responsabilidades, remuneraciones, haberes pasivos, permutas, licencias y demás particularidades que afecten a 
los funcionarios) (artículo 187 de la Ley de 1935), regulados desde esta legislación general para los Cuerpos nacionales, si bien con el carácter de mínimo, en parte, que les da el texto del artículo 48, de especial mención. "Tanıo lo dispuesto en este Reglamento respecto a la edad para la jubilación, como lo concerniente al haber pasivo de los jubilados y de las pensiones a sus viudas e hijos, se entenderán. sin perjuicio de lo establecido en los Reglamentos que los Ayuntamientos tengan aprobados, siempre que sus disposiciones resulten más favorables al Secretario.»

De lo dicho se deduce la preexistencia:

a) De normas legislativas de aplicación a los Cuerpos nacionales, con expresa declaración de derechos y deberes, susceptible de mejorarse por arbitrio de la facultad reglamentaria municipal (ař tículo 48).

b) De normas le gislativas para la declaración de deberes y derechos que no están definidos, atribuída-la declaración-a la facultad reglamentaria municipal y que se proyectarán sobre los funcionarios (art. 248 del Estatuto municipal, 93 bis del Reglamento de 1924 y 187 de la Ley de 1935).

Conviene destacar al mejor orden de nuestro trabajo la diferencia que, por simple, salta a la vista: Por las primeras de estas normas se ratifican y posiblemente mejoran unos derechos preexistentes. Por las segundas se creará y dará vida, en forma de ordenación juridica interior, a una relación de derechos y deberes que hasta el acto de la declaración no existían.

Lo expuesto, con los condicionales "por lo menos", "al menos", "como mínimo", al uso en nuestro Derecho, es bastante para comprender, sin discusión, la liberalidad de las Corporaciones, para conceder beneficios a sus funcionarios en el uso de su potestad reglamentaria. A pesar de esto, no falta quien con grave error, a nuestro juicio, y un tanto confundido por la terminología de ciertos preceptos, nieguen esta.liberalidad al punto de creer $\mathrm{y}$, a veces con tesón digno de mejor empleo, sostener que el Ayuntamiento, en su facultad, no puede rebasar las estipulaciones de los Reglamentos generales en cuanto a concesiones en haberes, tiempo para jubilación, etc., basando su criterio én que las excepciones del artículo 48 y sexta disposición transitoria del Reglamento de 1924 se contraen exclusivamente a los derechos que los funcionarios tenían a la promulgación de estas disposiciones, y que toda nueva ordenación de régimen interior se ha de ajustar a la medida del párrafo final del ar- 
tículo 1..$^{\circ}$ del Decreto de 14 de mayo de 1928 , criterio que no es exclusivo de regidores, sino que en la práctica hemos visto presidir o inspirar resoluciones de Gobiernos civiles, pronunciadas en el trámite del párrafo $2 .^{\circ}$ del artículo 93 bis en relación con el 168 del Estatuto, iuzgándose de anomalía la concesión de beneficios con exceso de los estipulados en las disposiciones generales.

Nunca más oportuna la transcripción de estos preceptos que reglan la acción del Gobierno civil en este trámite:

"Artículo 168.-Los Ayuntamientos enviarán a los Gobernadores civiles una copia certificada de las Ordenanzas municipales, Reglamentos y bandos generales de policía y buen gobierno que acuerden. El Gobernador civil podrá advertir a la Corporación municipal las infracciones legales o extralimitaciones que contengan.» "Si el Ayuntamiento insiste en mantener su texto primitivo, el Gobernador podrá trasladarlo al Fiscal de lo contenciosoadministrativo al sólo efecto de que interponga demanda ante el Tribunal provincial que resolverá sobre la legalidad o ilegalidad de las Ordenanzas en los extremos de su articulado que hayan producido la advertencia.» "Artículo 93 bis, párrafo 2. ${ }^{\circ}$ : De cada uno de estos Reglamentos se remitirá copia certificada al Gobernador civil, a los efectos del artículo 168 del Estatuto municipal, archivándose en las oficinas del Gobierno, a fin de que, en el caso de formularse algún recurso contenciosoadministrativo ante el Tribunal provincial, por vulneración de sus disposiciones. pueda surtir. sus efectos.)

Véase, el inciso es oportuno, cómo cualquier resolución gubernativa en este trámite ha de ajustarse a estas limitadas facultades ; es decir, recibir, advertir, trasladar al Fiscal, en su caso, y archivar los Reglamentos. El Gobernador civil no aprueba ni reprueba.

Es de advertir que el artículo 168 del Estatuto municipal quedó derogado por Decreto de 16 de junio de 1931, elevado al rango de Ley en 16 de septiembre de 1931.

$\mathrm{Y}$ esto sentado, pasemos a demostrar lo infundado de tales recusaciones :

a) Artículo 48 del Reglamento de 1924: Motívase esta discrepancia por la forma; mejor dicho, por la dicción verbal «tengan aprobado.n

La explicación es elemental, y poca gramática hemos de remover para encontrarla: La acción del verbo en modo subjuntivo no se retrotrae, cual se pretende, en falsa interpretación, a fechas ante- 
riores al tiempo presente con que, en apariencia, se expresa. Adviértase que este tiempo, démosle por presente, de subjuntivo, no concuerda ni construye, de por sí, con ningún complemento circunstancial de tiempo y, por tanto, le cuadra, sin reproche, la teoría sancionada por la Real Academia de que dicha acción, en subjuntivo, es subordinada $y$ referida indistintamente al presente $y$ al futuro; $y$ en el caso que se interprete, se entenderá rectamente referida al momento de la jubilación o de la defunción.

Confírmase este criterio por la jurisprudencia. La más reciente, de 15 de marzo de 1945. La cuestión planteada en esta sentencia se limita a declarar: "Si el Ayuntamiento de V. A., al conceder como haber pasivo de jubilación al que fué Secretario de la Corporación durante más de treinta y cinco años la totalidad del sueldo que disfruta, se excedió de sus facultades y vulneró los preceptos legales que señalan solamente las cuatro quintas partes del sueldo regulador»), $y$ el Tribunal se pronuncia en la consideración de que: "También hay que tener presente que entre esos preceptos legales está el artículo 48 del Reg:lamento de Secretarios municipales, de 23 de agosto de 1924, que establece que lo dispuesto en el mismo queda supeditado a los Reglamentos que los Ayuntamientos tengan aprobados, siempre que resulten al Secretario más favorables, lo que patentiza que los Ayuntamientos están facultados para poder fijar mayores cantidades a las jubilaciones de sus Secretarios que las consignadas en el Reglamento y Estatuto municipal.»)

b) Disposición 6. ${ }^{\text {a }}$ transitoria del mismo Reglamento: «Lo dispuesto en este Reglamento respecto a derechos de funcionarios municipales de cualquier categoría y clase no será óbice para que éstos sigan disfrutando los beneficios que los hubieran sido reconocidos por acuerdos anteriores.)

Como vimos en el lugar correspondiente, derechos de cierto tipo sólo se dispusieron con respecto a Secretarios, Interventores y algunos facultativos (médicos, farmacéuticos y veterinarios, artículo 106); pero nada se dispuso respecto a dichos beneficios para funcionarios municipales de otras categorías y clases, que quedaron para dispo.nerse en el acto de pronunciar la Corporación la declaración de derechos y deberes no definidos en la legislación general y atribuída en absoluto a la potestad reglamentaria del Ayuntamiento. Luego si a este precepto se le da el alcance restrictivo de que sólo tengan beligerancia los derechos dispuestos en el Reglamento general y los 
reconocidos por acuerdos municipales anteriores, la resultante será que los funcionarios municipales de otras categorías y clases que no fueran los Cuerpos nacionales y facultativos, y a quienes acuerdos anteriores no hubieran reconocido derechos de este tipo, se verían privados, en el interregno, de los beneficios dinerarios y de previsión, que no les fueron definidos por el Reglamento general, ni reconocidos por acuerdos municipales anteriores; interpretación y consecuencia absurda e imposible y contraria, desde luego, al mandato del articulo 248 del Estatuto y 93 bis del Reglamento, que establecieron el imperativo de su concesión.

c) Decreto de 14 de mayo de 1928: Imprescindible de todo punto consignar aquí sus antecedentes:

Fué una laguna del Estatuto la omisión del plazo para la aprobación por los Ayuntamientos de sus Reglamentos. A remediarlo, creemos, acudió, sin duda, el párrafo final de la segunda disposición transitoria, cuyo texto confirma la ausencia de una completa relación de derechos y deberes: "Los nombramientos de empleados administrativos y tẹ́cnicos que hagan los Ayuntamientos antes de la aprobación de los respectivos Reglamentos orgánicos de cada Corporación. tendrán carácter interino.»

Se intentaba provocar así el estímulo de las Corporaciones a esta tarea; pero, con más visión de la indolencia habitual de nuestros Municipios, el Ministerio, por R. O. de 30 de diciembre de 1924, hubo de emplazar a los Ayuntamientos a cumplir aquella obligación antes del día 30 de junio de 1925 , considerando decaídos de su derecho a los que no lo hicieren y conminándoles a la imposición de un Reglamento provisional que regiría mientras la Corporación municipal to elaborase otro. $Y$ así, en la persistente abulia municipal se dicta el de 1928, cuyo artículo 1.० dice: "Mientras que las Corporaciones no den cumplimiento al artículo 248 del Estatuto municipal y 93 bis del Reglamento de Secretarios y empleados municipales, de 23 de agosto de 1924, aprobando y poniendo en vigor un Reglamento de funcionarios administrativos municipales, adoptarán y observarán el presente Reglạmento orgánico provisional en todas sus partes.) "A medida que dichas entidades vayan aprobando el que les ordena el Estatuto municipal vigente, dejará de regir éste en las que 1o hicieren, siempre que se atengan a los preceptos del artículo 248 del Estatuto y 93 del Reglamento citado y al contenido del presenti.." La discrepancia en este apartado, no aclarada en lo que hasta aho. 
ra llevamos dicho, surge del término “y al contenido del presente», para el que no puede admitirse el sentido restrictivo que pretende dársele como para que los Ayuntamientos no puedan alterar los términos del Reglamento de 1928, con tendencia a una mayor perfección de los servicios y mejorando los derechos de los funcionarios. Tal prevención tiende sólo al aseguramiento de normas y principios que se estiman fundamentales o mejor dicho mínimos, pues si la potestad reglamentaria (la obligación de ejercerla en forma de Reglamento interior) se considerara medida, exactamente con el contenido del de 1928, demás está el que nadie se moleste en hacer reglamentos; el suyo es el de 1928.

Pero esto no es así, porque si así fuera, resultaría que aquellos Ayuntamientos que no cumplieron a su tiempo la obligación de ordenar el régimen de deberes y derechos de sus empleados, se verian privados o cercenados notablemente en su potestad reglamentaria; y en el Decreto no existe precepto con alcance correctivo, derogatorio ni restrictivo para tan remoto antojo, siendo la regulación que se establece en el Decreto típicamente condicionada y transitoria o temporal por el tiempo que se tarde en redactar la propia del $\mathrm{Mu}$ nicipio moroso.

De todo lo expuesto se deduce:

1. Que la Corporación municipal, en uso de su potestad reglamentaria, puede conceder a sus funcionarios mayores beneficios de sueldos y de previsión que los fijados en las disposiciones generales.

2. Que la acción del Gobierno civil no aprueba ni desaprueba los Reglamentos, limitándose a advertir cualquier infracción legal que observare y, en su caso, a trasladar al Fiscal de lo Contencioso los expedientes.

$\mathrm{Y}$ para terminar, diremos que en la nueva Ley de Bases es menos confusa la terminología: (ni unos ni otros (los Reglamentos), podrán contener preceptos opuestos a las leyes».

A nadie se le ocurrirá pensar que, conceder a un jubilado o a un pensionista derechos superiores a los mínimos con propósito de liberarlos de una miseria segura, por ejemplo, es oponezse a la Ley. Oponerse a la Ley sería, por el contrario, negar los escasos derechos reconocidos por ésta o declararlos en inferior medida o. cantidad.

Mas la disputa, a punto está de concluir: Nuestra condición de ponente para informar sugerencias para la reglamentación de la: 
Ley articulada en el Congreso de los Cuerpos Nacionales celebrado en el mes de junio de 1946, nos proporcionó la satisfacción (y lo decimos cuando ello ha sido publicado incluso por revistas profesionales) de ver cómo el texto de determinado artículo de dicha Ley, al desarrollar esta Base, poco más o menos, decía:

«Los Ayuntamientos formarán sus reglamentos de personal; éstos no podrán contener preceptos que mermen los beneficios que se estipulan en las disposiciones de carácter general, pudiendo en cambio mejorarlos en la medida de sus posibilidades.)

Para todos nuestra enhorabuena, y a los Poderes públicos nuestra gratitud porque nos quita, con esta elocuente declaración, del espinoso camino de nuestra actividad profesional, estas injustificadas controversias.

\section{Antonio Rodríguez Gerez}

Secretario del Ayuntamiento de Montemaynr (Córdoba) 